\title{
Application of multi-enzymatic hydrolysis for improving the efficiency of the biogas production in solid waste fermentation process in Ostróda WWTP
}

\author{
Kamil Lipiński ${ }^{1, *}$, and Katarzyna Umiejewska ${ }^{1}$ \\ ${ }^{1}$ Warsaw University of Technology, Faculty of Building Services, Hydro and Environmental \\ Engineering, ul. Nowowiejska 20, 00-653 Warsaw, Poland
}

\begin{abstract}
Biomass fermentation is one of the important sources of renewable energy in EU. Application of multi-enzymatic hydrolysis process enables a significant increase in efficiency of biogas production. The main goal of the paper is to present the results of the pilot scale research performed in WWTP in Ostróda. The fixed combination of three enzymes was continiously introduced: amylase, lipase and protease. Research aimed at verifying the impact of enzyme dose on sludge digestion process and on the amount of biogas produced. Statistical analysis of the research results allows to determine the influence of dosing the enzymes in mesophilic digestion on the biogas production.
\end{abstract}

\section{Introduction}

Sewage sludge is an inherent product of the operation on WWTP. The most common method of stabilization is anaerobic digestion. The efficient production and use of biogas in a WWTP is a source of heat and power. Multi-enzymatic hydrolysis is a biological technology of primary disintegration of sewage sludge. It accelerates and improves the efficiency of the natural process of hydrolysis [1] occurring in the first stage of sludge digestion, uses a number of naturally produced [2] or additionally dosed forms of [3] enzymes: amylase, protease [4] and lipase [5], which reduce the activation energy of the hydrolysis of selected organic compounds. As a result, the percentage of biodegradable organic matter increases, which provokes the increase in the efficiency of biogas production.

The aim of the study was to determine whether the method of multi-enzymatic hydrolysis improves the efficiency of the sludge digestion process from the treatment plant in Ostróda and if it increases the biogas production during the mesophilic digestion.

\footnotetext{
${ }^{*}$ Corresponding author: kamil.lipinski.pl@.gmail.com
} 


\section{Materials and methods}

The research was conducted in a pilot scale in the period 05.10.2011-31.07.2012 in the Ostróda WWTP belonging to PWiK Ostroda sp. z. o.o.

There were three series of tests:

- Series I. Start-up and stabilization of the mesophilic digestion process in the period of 05.10.2011-08.12.2011

- Series II. Sludge mesophilic digestion with the dosage of the enzymes with $20 \%$ of dry solids concentration, in the period of 09.12.2011-26.03.2012

- Series III. Sludge mesophilic digestion with the dosage of the enzymes with $10 \%$ of dry solids concentration in the period of 27.03.2012-31.07.2012

The model consisted of a feed tank with a capacity of 1130 litres for the continuously supplied primary and excess sludge, mixed in equal proportions. The sludge from the feed tank was directed to a digester with a capacity of 1410 litres. In Series I the temperature in the digester was $38^{\circ} \mathrm{C}$, HRT $=35$ days. In the Series II and III, the enzymes were dosed to the feed tank in an amount of 20 and $10 \%$ dry mass. In the Series III, the temperature was lowered to $35^{\circ} \mathrm{C}$ and the sludge HRT was reduced to 29 days. Digested sludge was directed to the final tank.

The scope of the research included the measurement of the parameters in raw and digested sludge and the volume of produced biogas. The daily volume of biogas was measured and calculated to the volume of the biogas produced from dry organic mass contents (Q demonstrates the effectiveness of decomposition of organic compounds in the sludge.

Samples were collected at the feed tank (mixed sludge) and the final tank (digested sludge). The analysis of sludge parameters were made according to the following standards:

- Determination of dry matter PN-EN 12880:2004

- Determination of the loss of ignition of dry mass \% - PN-EN 12879:2004

- Determination of COD - PN-74/C-04578.03

\section{Results}

\subsection{Series I - start-up and stabilization of mesophilic digestion process}

After the start-up, the reactor worked in batch process and then in continuous one. The temperature in reactor was $38^{\circ} \mathrm{C}$, and the HRT was 35 days. Table 1 shows the sludge quality before and after digestion process during series I and the calculated digestion index.

At the beginning of the research, the dry matter content (DM) in the raw sludge was in the range of 5-6\%. The content of the organic dry matter (ODM) remained at a high level oscillating around $78-80 \%$. The COD value was usually over $60000 \mathrm{mg} / \mathrm{L}$. The dry matter content of digested sludge, which first was low (1.7\%), experienced a period of rapid growth to a $4.3 \%$, then declined and finally began to stabilise at around $3.1 \%$. The content of dry organic matter decreased from approximately $73 \%$ (the beginning of the study) to about $63 \%$. The actual value of the digestion index, at the start of work is very low $2-6.5 \%$ and next grew and ranged between 42.8-56.7. The COD value decreased from $56000 \mathrm{mg} / \mathrm{L}$ (the beginning of the study) and was about $32000 \mathrm{mg} / \mathrm{L}$. 
Table 1. shows the sludge quality before and after digestion process during series I and the calculated digestion index.

\begin{tabular}{|c|c|c|c|c|c|c|c|}
\hline \multirow{2}{*}{ Date } & \multicolumn{9}{|c|}{ Sludge } \\
\cline { 2 - 8 } & \multicolumn{3}{|c|}{ From feeding tank } & \multicolumn{4}{c|}{ After digestion } \\
\cline { 2 - 8 } & DM & ODM & COD & DM & ODM & COD & Digestion index \\
\cline { 2 - 8 } & $\%$ & $\% \mathrm{DM}$ & $\mathrm{mg} / \mathrm{L}$ & $\%$ & $\% \mathrm{DM}$ & $\mathrm{mg} / \mathrm{L}$ & $\%$ \\
\hline $2011-10-17$ & 6.1 & 77.0 & 60000 & 1.7 & 75.8 & - & 6.5 \\
\hline $2011-10-25$ & 5.6 & 73.7 & 32100 & 4.3 & 73.3 & 56000 & 2.0 \\
\hline $2011-11-15$ & 5.6 & 76.3 & 60000 & 3.3 & 63.6 & 31400 & 45.7 \\
\hline $2011-11-22$ & 5.0 & 78.7 & 60000 & 3.1 & 63.9 & 32800 & 42.8 \\
\hline $2011-11-24$ & 5.1 & 78.2 & 59600 & 3.1 & 64.0 & 31900 & 44.6 \\
\hline $2011-11-29$ & 4.9 & 79.7 & 60000 & 3.1 & 63.7 & 31400 & 49.7 \\
\hline $2011-12-01$ & 5.2 & 80.0 & 60000 & 3.1 & 63.4 & 32600 & 53.6 \\
\hline $2011-12-06$ & 5.2 & 80.7 & 60000 & 3.1 & 62.4 & 32400 & 56.7 \\
\hline
\end{tabular}

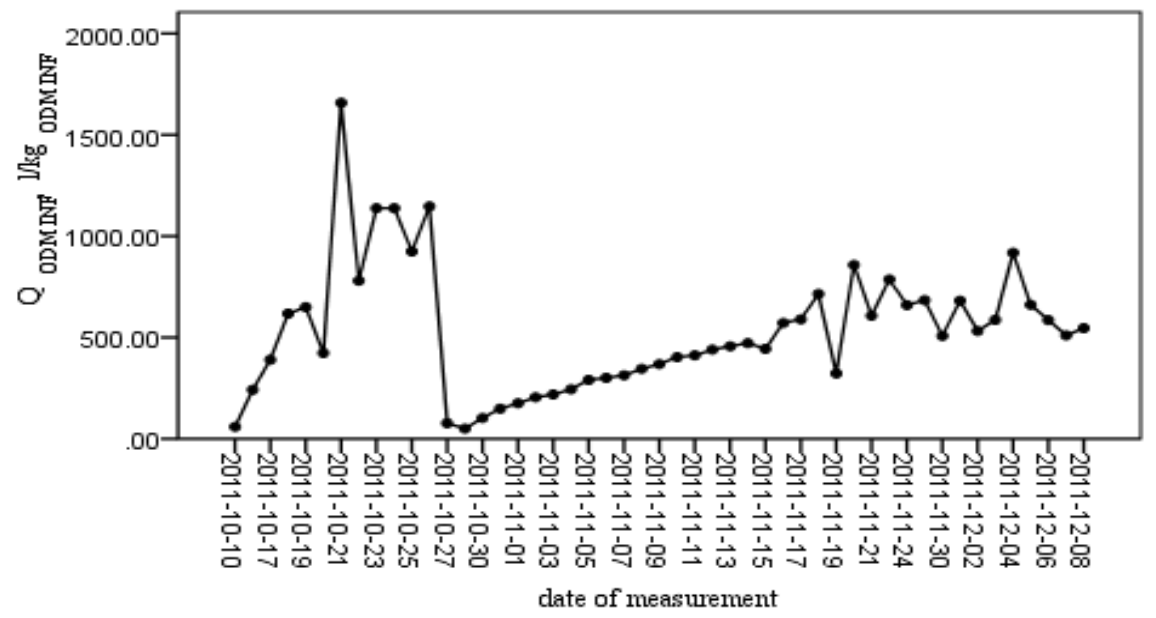

Fig. 1. The volume of biogas produced in the Series I.

In the series I, a far reaching variation of biogas production might be observed (Fig. 1). The stabilisation of the digestion process was preceded by some significant changes in the biogas production expressed by Q ODM INF 400-900 1/ $\mathrm{kg}$ ODM INF.

\subsection{Series II - enzyme dosage of $20 \%$ contents dry solid}

Before the start of the series II, a stabilization work without the addition of enzymes was achieved. Thus, decisions have been taken about dosage of enzymes. Enzymes were dosed directly into the feed tank in an amount of $20 \%$ of dry matter. Table 2 shows the sludge quality before and after the digestion process during series II and the calculated digestion index.

The dry matter content in the raw sludge in series II showed considerable variation, the trend of decreasing the level of 5-6\% to $3-4 \%$. The content of organic dry matter remained at a high level oscillating between $78 \%$ and $85 \%$, but in this case, at the end of the 
experiment, the occurrence of a significant downward trend could be observed. Sludge COD value was located outside the range of the measurement $(60000 \mathrm{mg} / \mathrm{L})$ not as often as in the series I. In February, in a period of intense cold, the sludge COD dropped significantly to the level of $30800 \mathrm{mg} / \mathrm{L}$. Later, it returned to the level of $40000-50000 \mathrm{mg} / \mathrm{L}$.

The decrease in dry matter content in the raw sludge caused the decline in dry matter content in sludge after the mesophilic digestion process to the level of $2.4-3.2 \%$. The content of dry organic matter in the digested sludge was $62-63 \%$ before starting the dosage of enzymes and increased to $64-68 \%$ as a result of dosing enzymes. The calculated actual digestion index has a high variability within the range of $27.3-65.3 \%$ (average $52.1 \%$ ).

COD value of digested sludge remained relatively stable compared to the changing raw sludge that was supplied. However, it decreased from above $28600 \mathrm{mg} / \mathrm{L}$ from the period before the frost to the level of $24100-27400 \mathrm{mg} / \mathrm{L}$.

Table 2. Parameters in the raw and digested sludge obtained in the series II.

\begin{tabular}{|c|c|c|c|c|c|c|c|c|}
\hline \multirow{2}{*}{ Date } & \multicolumn{7}{|c|}{ Sludge } \\
\cline { 2 - 8 } & \multicolumn{7}{|c|}{ From feeding tank } & \multicolumn{4}{c|}{ After digestion } \\
\cline { 2 - 8 } & DM & ODM & COD & DM & ODM & COD & $\begin{array}{c}\text { Digestion } \\
\text { index }\end{array}$ \\
\cline { 2 - 8 } & $\%$ & $\%$ DM & mg/L & $\%$ & $\%$ DM & mg/L & $\%$ \\
\hline $2011-12-13$ & 5.0 & 82.8 & 60000 & 3.0 & 63.9 & 32300 & 58.9 \\
\hline $2011-12-20$ & 5.2 & 78.5 & 60000 & 3.2 & 62.4 & 31300 & 61.7 \\
\hline $2011-12-27$ & 4.9 & 82.4 & 60000 & 3.0 & 62.8 & 31400 & 64.5 \\
\hline $2012-01-03$ & 4.7 & 83.4 & 58500 & 3.1 & 63.2 & 31600 & 65.8 \\
\hline Sludge digestion with the dosage of the enzymes with $20 \%$ of dry solids concentration \\
\hline $2012-01-10$ & 4.6 & 82.1 & 54400 & 3.0 & 64.7 & 37000 & 37.7 \\
\hline $2012-01-17$ & 4.9 & 82.0 & 58400 & 2.9 & 64.6 & 26000 & 37.7 \\
\hline $2012-01-24$ & 5.4 & 83.9 & 37800 & 2.9 & 66.4 & 10600 & 38.5 \\
\hline & $31.01 .2012-13.02 .2012$ The period of very low temperatures & \\
\hline $2012-01-31$ & 5.6 & 84.9 & 60000 & 2.9 & 66.5 & 28900 & 41.3 \\
\hline $2012-02-07$ & 4.0 & 84.3 & 48300 & 2.9 & 67.1 & 27800 & 37.8 \\
\hline $2012-02-14$ & 5.1 & 84.9 & 60000 & 2.8 & 68.5 & 26700 & 35.7 \\
\hline $2012-02-21$ & 6.0 & 84.4 & 60000 & 2.8 & 68.0 & 27000 & 35.5 \\
\hline $2012-02-28$ & 4.5 & 82.2 & 51100 & 2.6 & 67.8 & 29300 & 28.8 \\
\hline $2012-03-06$ & 4.0 & 82.4 & 52100 & 2.8 & 65.1 & 26400 & 44.6 \\
\hline $2012-03-08$ & 3.0 & 76.5 & 30800 & 2.4 & 67.6 & 24100 & 8.7 \\
\hline $2012-03-13$ & 2.9 & 79.9 & 41200 & 2.7 & 63.6 & 25700 & 49.9 \\
\hline $2012-03-22$ & 3.7 & 77.9 & 46600 & 2.6 & 66.1 & 27400 & 51.5 \\
\hline
\end{tabular}


In the Series II there was an increase in the average daily production of biogas during the dosing of enzymes (Fig. 2). The significance of this observation becomes apparent when comparing the value of Q ODM INF before and after enzyme dosing. The efficiency of biogas production increased from an average of $600 \mathrm{l} / \mathrm{kg}$ of dry organic matter to the level of $900 \mathrm{l} / \mathrm{kg}$ of dry organic matter. In addition, it was observed that although initially the decline in the content of the raw sludge dry mass was not included in the enzymes dosage which therefore exceeded $20 \%$, significant differences in the biogas production efficiency were not observed. The dose of enzymes, which was calculated based on previous laboratory tests, could therefore be too high. That is why the dose of enzymes with $20 \%$ to $10 \%$ dry solid concentration was changed, in order to optimise the dose in the future.

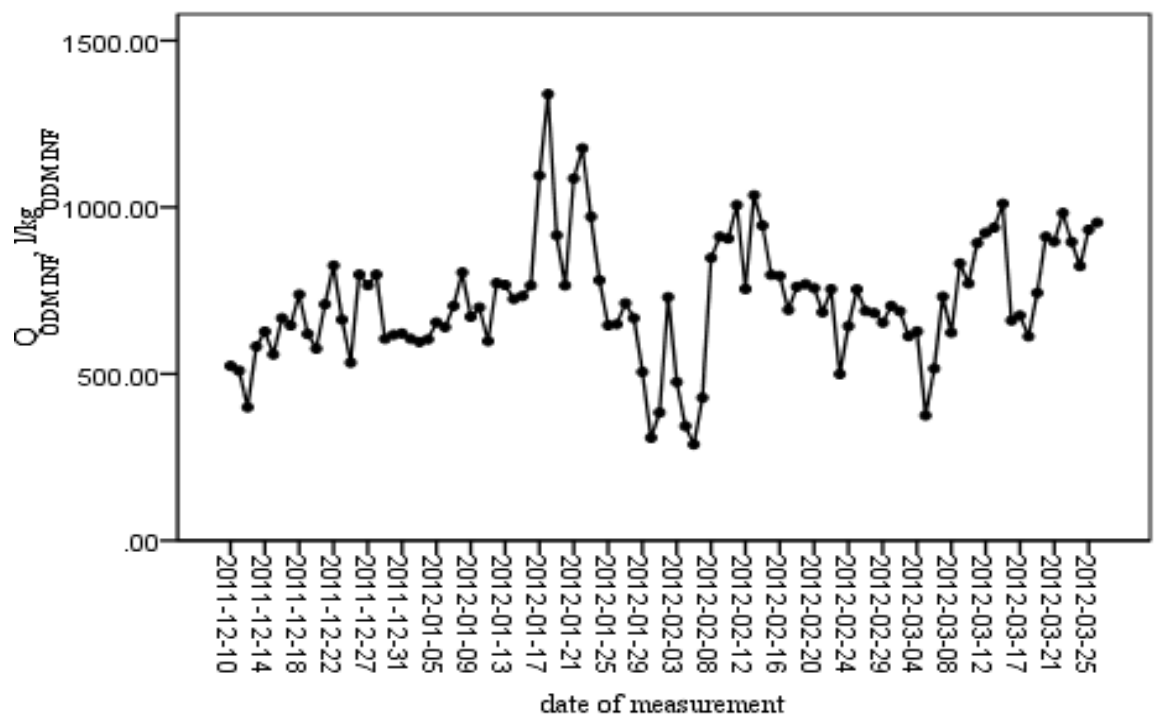

Fig. 2. The volume of biogas produced in the Series II.

\subsection{Series III - enzyme dosage of $10 \%$ contents of dry solid}

The purpose of Series III is to check if a lower dose of enzymes (content $10 \%$ dry solid) will have a comparable effect on the efficiency of biogas production. In this series, the sludge HRT was reduced to 29 days, and the temperature was lowered to $35^{\circ} \mathrm{C}$. Table 3 shows the sludge quality before and after the digestion process during Series III and the calculated unit of fermentation.

Dry matter content in the raw sludge in the Series III showed a large variation in the range of $2.1-5.9 \%$. In this period, the organic dry matter content in the raw sludge was $80 \%$. A noticeable decrease to $65.3 \%$ was recorded in the summer. In July, the dry matter content significantly increased - more than $5 \%$ while the content of organic dry matter decreased to less than $70 \%$. Sludge COD value dropped to the level of $27700 \mathrm{mg} / \mathrm{L}$, then rose to the level of the maximum measurable excess of $60000 \mathrm{mg} / \mathrm{L}$.

Digestion conditions during the Series III remained stable, despite the changes in the quality of raw sludge. The dry matter content was in the range of $2.2-3.6 \%$. The dry organic matter was lower than in the Series II - in the range of 54.7-63.3\%. The calculated actual digestion index exceeds $50 \%$. The value of COD of the sludge was in the range 19000-30500 mg/L. 
Table 3. Parameters in the raw and digested sludge obtained in the Series III.

\begin{tabular}{|c|c|c|c|c|c|c|c|}
\hline \multirow{4}{*}{ Date } & \multicolumn{7}{|c|}{ Sludge } \\
\hline & \multicolumn{3}{|c|}{ From feeding tank } & \multicolumn{4}{|c|}{ After digestion } \\
\hline & DM & ODM & COD & DM & ODM & COD & $\begin{array}{c}\text { Digestion } \\
\text { index }\end{array}$ \\
\hline & $\%$ & $\% \mathrm{DM}$ & $\mathrm{mg} / \mathrm{l}$ & $\%$ & $\% \mathrm{DM}$ & $\mathrm{mg} / \mathrm{l}$ & $\%$ \\
\hline 2012-03-29 & 4.4 & 78.8 & 54200 & 2.6 & 62.0 & 30500 & 58.4 \\
\hline 2012-04-10 & 3.3 & 79.2 & 41400 & 2.5 & 63.3 & 25000 & 52.0 \\
\hline 2012-04-17 & 2.1 & 72.4 & 27700 & 2.4 & 61.7 & 25300 & 53.3 \\
\hline \multicolumn{8}{|c|}{ Sludge digestion with the dosage of the enzymes with $10 \%$ of dry solids concentration } \\
\hline 2012-04-24 & 4.2 & 80.8 & 60000 & 2.4 & 59.6 & 29100 & 53.4 \\
\hline 2012-05-08 & 2.8 & 78.9 & 42300 & 2.3 & 62.0 & 21900 & 50.3 \\
\hline $2012-05-15$ & 2.7 & 76.4 & 40000 & 2.5 & 59.2 & 19000 & 55.5 \\
\hline $2012-05-22$ & 2.7 & 77.3 & 36200 & 2.5 & 57.9 & 21700 & 45.7 \\
\hline $2012-05-29$ & 3.0 & 78.3 & 50100 & 2.3 & 59.9 & 22600 & 58.6 \\
\hline 2012-06-05 & 3.8 & 77.0 & 53800 & 2.4 & 58.4 & 29000 & 58.1 \\
\hline \multicolumn{8}{|c|}{ Batch work } \\
\hline 2012-06-12 & 3.0 & 77.8 & 38300 & 2.2 & 62.2 & 23400 & 53.0 \\
\hline $2012-06-22$ & 4.2 & 73.8 & 61200 & 2.6 & 54.7 & 22800 & 57.1 \\
\hline $2012-06-28$ & 5.9 & 73.6 & 60000 & 2.8 & 53.9 & 24100 & 58.1 \\
\hline $2012-07-05$ & 3.9 & 69.6 & 41400 & 3.0 & 56.6 & 27000 & 43.0 \\
\hline $2012-07-13$ & 5.0 & 70.9 & 60000 & 3.1 & 55.8 & 26000 & 48.2 \\
\hline 2012-07-19 & 5.4 & 66.5 & 60000 & 3.2 & 54.7 & 28600 & 39.2 \\
\hline $2012-07-26$ & 5.2 & 65.3 & 60000 & 3.6 & 62.2 & 28100 & 12.6 \\
\hline
\end{tabular}

In the Series III there was a decrease in the average daily production of biogas because the dry matter content in the raw sludge decreased. Organic compounds are the material for methanogenic bacteria. The decrease in the enzyme dose could cause a Q ODM INF decrease, which could be associated with the lower efficiency of multi- enzymatic hydrolysis process. Finally, reducing HRT from 35 to 29 days could reduce the efficiency of biogas production. The reasons for the decline in production are therefore complex and require further analysis. 


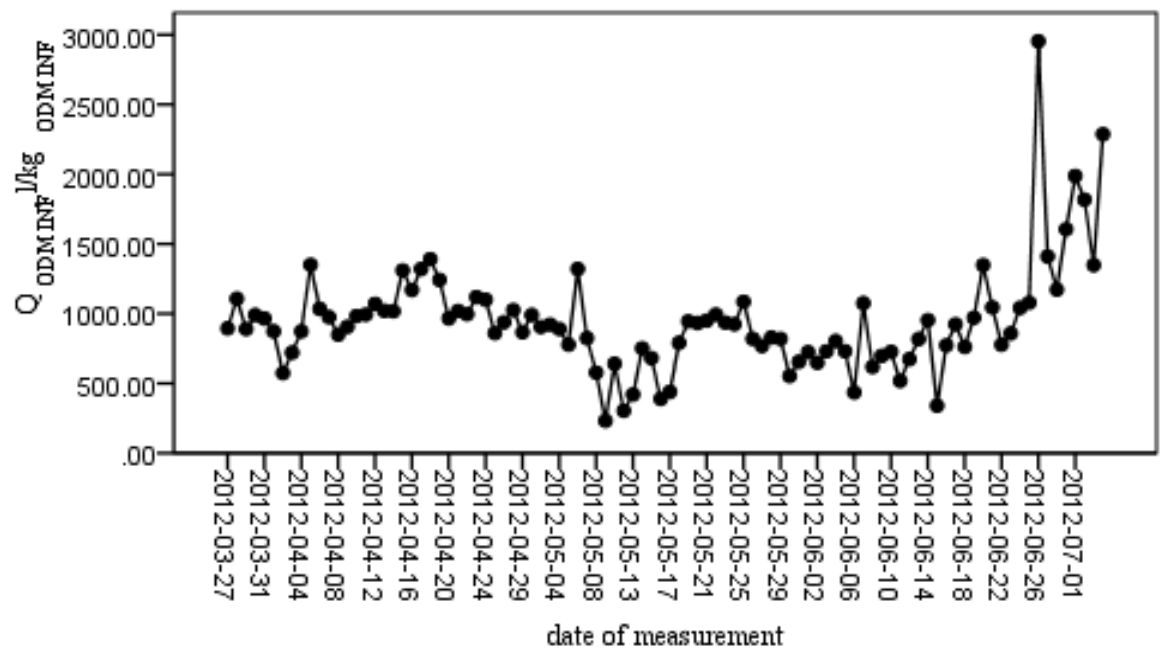

Fig. 3. The volume of biogas produced in the Series III.

During the series III we have managed to achieve an intriguing but inconclusive research. Double dose reduction enzymes with $20 \%$ contents of dry matter to $10 \%$, influenced the course of the process, but in a decidedly ambiguous way. The amount of biogas produced Q ODM INF in Series II and III was on the same level.

\section{Discussion}

\section{Verification of hypotheses}

To systematize conducted analysis, focused on the influence of multi-enzymatic hydrolysis on the efficiency of biogas production, two following research hypotheses were elaborated.

H I. In the process of mesophilic sludge digestion, enzyme dosing increases the efficiency of biogas production.

In the first stage of hypotheses verification, mean values and standard deviation of QODM INF were compared. In the series II and III (dosing of enzymes) higher mean value Q ODM INF. The difference of Q ODM INF value in series was initially estimated at $219.71 / \mathrm{kg}$ ODM INF $(34.5 \%$ increase).

Table 4. Biogas production Q ODM INF and enzymes dosing.

\begin{tabular}{|c|c|c|}
\hline Dosage of the enzymes & Mean Q ODM INF & Standard Deviation \\
\hline No (Series I) & $636.01 / \mathrm{kg}$ ODM INF & $122.61 / \mathrm{kg}$ ODM INF \\
\hline Yes (Series II and III) & $855.71 / \mathrm{kg}$ ODM INF & $331.21 / \mathrm{kg}$ ODM INF \\
\hline
\end{tabular}

Second stage of the analysis in the process of verification of potential relation between variables was generating a model of linear regression and testing the stastical significance of generated model. Statically important model $\left(\mathrm{Chi}^{2}=0.000, \mathrm{R}^{2}=0.086\right.$, ANOVA significance $=0.000$ ) was obtained. It allowed to estimate following linear regression equation, assessing statically important, positive influence of enzyme dosing on biogas production in mesophylic digestion. 


$$
Q_{O D M I N F}=636.0+219.7 \cdot \mathrm{e}\left[1 / \mathrm{kg}_{\text {ODM INF }}\right]
$$

e: dosing of enzymes $(0=$ no; 1 = yes $)$ (dummy variable)

H II. In the process of mesophilic sludge digestion, linear effect of enzyme dosing on biogas production is observed.

To assess the size of optimal enzymes dose, mean values and standard deviations of Q ODM INF for different sizes of doses effects were compared. For analysed data, the highest level of Q ODM INF can be observed for size of dose $10 \%$ of dry solids concentration in fermentation chamber.

Table 5. Biogas production Q ODM INF and size of enzymes dose.

\begin{tabular}{|c|c|c|}
\hline Size of enzyme dosage & Mean Q oDM INF & Standard Deviation \\
\hline no dosage & $636.01 / \mathrm{kg}$ ODM INF & $122.61 / \mathrm{kg}$ ODM INF \\
\hline $10 \%$ of dry solids concentration & $899.11 / \mathrm{kg}$ ODM INF & $411.71 / \mathrm{kg}$ ODM INF \\
\hline $20 \%$ of dry solids concentration & $827.11 / \mathrm{kg}$ ODM INF & $263.21 / \mathrm{kg}$ ODM INF \\
\hline
\end{tabular}

To verify observation, model of linear regression was generated. Preliminary analysis suggested considerably low explanatory potential of the linear model of enzyme dose influence $\left(\mathrm{Chi}^{2}=0.001 ; \mathrm{R}^{2}=0.037\right.$; ANOVA significance $\left.=0.001\right)$. To analyse the potentially non-linear relation between size of enzymes dose and biogas production, the size of dose data were recoded into two 0-1 "dummy variables" for each size of enzyme dosage: $\mathrm{e}_{20}\left(20 \%\right.$ of dry solids concentration) and $\mathrm{e}_{10}$ ( $10 \%$ of dry solids concentration). The second model that was generated was statistically significant $\left(\mathrm{Chi}^{2}=0.000, \mathrm{R}^{2}=0.096\right.$, ANOVA significance $=0.000$ ). It allowed to estimate following linear regression equation, assessing statically important, positive influence of size of dose of enzymes on biogas production in mesophylic digestion of sewage sludge.

$$
Q_{O D M I N F}=636,0+263,1 \cdot \mathrm{e}_{10}+191,1 \cdot \mathrm{e}_{20}\left[1 / \mathrm{kg}_{\mathrm{ODM} \mathrm{INF}}\right]
$$

$\mathrm{e}_{10}$ : Enzyme dose $10 \%$ of dry solids concentration $(0=\mathrm{no})(1=\mathrm{yes})$ (dummy variable) $\mathrm{e}_{20}$ : Enzyme dose $20 \%$ of dry solids concentration $(0=$ no) $(1=$ yes) (dummy variable)

The production of biogas was proven more effective for $10 \%$ dry solids enzyme dose. The relation between variables was presented with three equations, representing separate influence of $10 \%$ ds and $20 \%$ DM enzyme dose. The positive influence of optimal dose of enzymes, $10 \%$ of dry solids, on biogas production was estimated on $263.11 / \mathrm{kg}_{\text {ODM INF }}(41 \%$ increase). Last equation, QODM INF_e10, represents the negative influence of enzymes over the optimal $10 \%$ dry solids dose.

$$
\begin{aligned}
& Q_{O D M I N F}=636.0+263.1 \cdot \mathrm{e}_{10}\left[1 / \mathrm{kg}_{\text {ODM INF }}\right] \\
& Q_{O D M I N F}=636.0+191.1 \cdot \mathrm{e}_{20}\left[1 / \mathrm{kg}_{\text {ODM INF }}\right] \\
& Q_{O D M I N F E 10}=899.1-191.1 \cdot \mathrm{e}_{20}\left[1 / \mathrm{kg}_{\text {ODM INF }}\right]
\end{aligned}
$$




\section{Conclusion}

Studies show that there is a positive relationship between enzyme dosing and the increased productivity of biogas production in mesophilic fermentation. The results allow us to estimate that the enzyme dosage allows for an increase in the production of biogas from kilogram of organic dry mass of $48 \%$. The analyses indicated that in the case of mesophile fermentation, statistically there is no significant relationship between the increase of enzyme dose and the increase of biogas production. The data obtained suggests that the increase in the dose of more than $10 \%$ of dry mass may even cause a decrease in biogas production.

Acknowledgment for $d r$. R. Wasiak for preparing modern application of multi-enzymatic hydrolysis technology and SEEN Technology for sharing the data.

\section{References}

1. W. Parawira Crit. Rev. Biotechnol. 32, 2, 172-186 (2011)

2. S. Yu, G. Zhang, J. Li, Z. Zhao, X. Kang, Bioresour. Technol. 146, 758-761 (2013)

3. S. Kavitha, S. Adish Kumar, K.N. Yogalakshmi, S.Kaliappan, J.Rajesh Banu, Bioresour. Technol. 150, 210-219 (2013)

4. Q. Yang, K. Luo, X.M. Li, D. B Wang, W. Zheng, G.M Zeng, J.J Liu, Bioresour. Technol. 101, 2924-2930 (2010)

5. A. Donoso-Bravo, M. Fdz-Polanco, Process Biochem. 48, 936-940 (2013) 